\title{
Research on the Integration Advantages of Physical Education and Computer Technology in College
}

\author{
Jianzhen Huang ${ }^{1}$, Yuntian Huang ${ }^{2}$ \\ ${ }^{1}$ Nanchang Institute of Science and Technology, Department of Physical Education, Jiangxi, \\ Nanchang 330108; \\ ${ }^{2}$ Nanchang Institute of Science And Technology, Department of Physical Education, Jiangxi, \\ Nanchang 330108
}

KEYWORDS: College, Physical Education, Computer Technology

\begin{abstract}
The 21st century is the era of network information, in this context, computer technology has been widely used in various fields. In recent years, combined with domestic teaching found in computer technology which is also widely used, and the high value significance. Computer technology penetration in College Physical Education, enabling college physical education innovation. This article focuses on how to College Physical Education and play integration advantages of computer technology to explore, to provide valuable reference for optimizing and improving the credentials College Physical Education.
\end{abstract}

\section{Introduction}

Under the traditional model, "indoctrination" physical education, "the theory and practice of light" sports teaching mode is difficult to improve students' motivation to learn [1]. Under conditions of increasing development of computer technology and mature, major colleges and universities computer technology and physical education integrated with each other, so that the sports teaching innovation in teaching students feel novel mode conditions, they are more willing to get involved with sports learning process, Further to optimize student learning sports laid a solid foundation. In view of this, the paper "College Physical Education and computer technology integration advantages" for analysis and exploration is of great significance.

\section{The Analysis on Key Points Needed to be Strengthened of Computer Technology in College Physical Education}

College Physical Education and integration between computer technology is not an overnight thing, we need to do to strengthen the various key points in the computer technology to reflect the value of the condition, which is integrated into the physical education, to be able to make physical education teaching optimize and improve. The key points to strengthen the specific needs include:

A. Strengthening the Construction of Hardware Facilities and Equipment.

Universities Sports Teaching Work and ultimately into the hardware facilities and equipment. If the hardware is not enough to strengthen the facilities and equipment, it will reduce the value of the computer, such as the processing efficiency of the computer reduces the memory capacity of a computer and the like is reduced. When these issues arise, the value of the role of computer 
technology in College Physical Education Teaching will be difficult to effectively reflected. To this end, strengthen the construction of hardware facilities and equipment has become one of the important key points.

\section{B. Strengthen Efforts in Building Software Environment.}

In mature software environment, and be conducive to the integration of computer technology between College Physical Education. For example, the advantages of network resources platform fully reflected, and then computer technology resources in University currently has a reasonable and scientific integration, so that will be able to achieve "cooperation" in the teaching mode to provide valid credentials for optimizing College Physical Education [2]. Therefore, in order to make computer technology and College Physical Education effectively reflect the advantages of integration, we need to strengthen efforts in building software environment.

\section{Strengthen Efforts to Develop Sports Network Information Resources.}

Since it is to carry out teaching, would be necessary in the integration of computer technology on the basis of the conditions existing in University teaching resources on the network, the network teaching resources for further expansion. For example, the use of computer technology and network teaching platform to strengthen ties between universities and colleges sports teaching resources sharing, so that the university sports information technology effectively to enhance teaching effectiveness. In short, in order to make the integration of computer technology and the advantages between College Physical Education are effectively represented, and strengthen efforts to develop sports network information resources it is very necessary.

\section{Strategy of Realization the Integration superiority of Physical Education and Computer Technology in College}

In the above analysis, in order to make the integration of the recognized advantages of college physical education and computer technology are effectively represented, from the need to strengthen a number of key points. But the College Sports teaching practice, I believe that in order to reflect the College Physical Education and computer technology integration advantages, but also the need for effective strategies. Specific strategies are as follows:

\section{A. Using Computer Technology To Make Sports Theoretical Teaching More Thorough}

Ultimately theoretical teaching any subject, it is in terms of college sports disciplines, including exercise physiology, sports psychology and other theoretical knowledge as well as rules of the game [3]. In the past, the process of teaching the theory, some theoretical knowledge to take "oral" Teaching Method is often difficult for students to fully understand, such as basketball is not enough understanding of students, teachers, oral presentations "hatchet man", "walking" and "three seconds when illegal "and other foul play, it is often difficult for students to understand. To this end, teachers will be able to use of computer technology, through the collection of network video resources by basketball classic example, allow students to visually watch some foul play, and teachers combined theoretical lectures, students will be able to deepen the understanding of the theory of knowledge , thus achieving the purpose of optimizing the teaching. In addition, through the effective integration of computer technology, but also can improve students' motivation to learn the theory of participation, so that the theory of teaching college sports to avoid boring traditional teaching, further demonstrate the innovation side. 


\section{B. The Use of Computer Technology Makes Physical Education Management More Optimization}

In Higher Education Management, including sports equipment, sports information, and file management, etc. [4]. In order to be able to reflect the university physical education management optimization side, it can make use of computer technology. For example, in sports equipment and site management process, using computer technology to build online personal responsibility to prepare teachers for the 1-2 sport-related equipment as well as custody of borrowing to conduct a comprehensive management through a computer terminal. As another example, in sports teaching archives management, the use of computer technology to achieve information management, improve the traditional paper-based records management deficiencies. At the same time, in physical education records management, the integration of computer technology conditions, but also need to focus on security files and confidentiality, in order to make college sports teaching archives management reflects a sound and comprehensive and scientific qualities.

\section{Using Computer Technology to Construct the Sports Education Platform.}

Time college physical education there is a certain limit, but if the site can use the platform to carry out physical education, you can not time and space constraints, both for teachers to save time, but also to enable students to obtain a reasonable time scientific arrangement. For this reason, the use of computer technology to build sports teaching platform will have a substantial role. On the one hand, by constructing sports teaching platform for teachers in sports where the shared knowledge, and then let the students to gain knowledge through the platform, it will not only enable students to grasp the real-time sports knowledge, but also to cultivate students' ability of independent study. On the other hand, through the construction of a sports platform, allowing teachers and students as a channel to communicate knowledge on the content, will be able to narrow the distance between teachers and students, in order to make sports teaching innovation, further optimize student learning provide valid credentials.

\section{Using Computer Technology to Show Science of Sports Teaching.}

Computer technology, the most obvious feature is that with the "technical", in order to make science teaching sports has been effectively demonstrated, can take full advantage of this feature of computer technology, to strengthen the technical arrangement of college physical education, technical simulation and analysis technology . To which the technical analysis, for example, by referring to the students' action sports technology, based on computer technology, sports technology student movements were analyzed to find out the malfunction, and in a timely manner to help students the wrong technology action corrected, so that students master the correct scientific technical action sports. For example: During the track and field project-based teaching, the students use the camera filmed the whole action sports, action will be taken and then input into the computer, and then complete the appropriate treatment [5]. On the basis of the student movement in the body node displacement, acceleration and the absolute speed and other parameters were analyzed, taking into consideration on the technical characteristics of the students and then track and field events in motion to conduct a detailed and scientific grasp, then promptly students erroneous motion technology corrected, so that students will be able to regulate the movement of technical movements, thereby enabling the student athlete and sports skills improved effectively. In short, in order to reflect sports science teaching, they can reasonably scientific application of computer technology, more full of college physical education and computer technology integration advantage. 


\section{Conclusion}

Through this study, recognizing that in order to make teaching and computer technology integration advantages of college sports are effectively represented, need to focus on several key points, including hardware and software development environment as well as to strengthen the network of sports information resources. At the same time, the need to effectively integrate computer technology under conditions and strengthen the theory teaching, teaching management, to build sports platform and focusing on technical analysis. Believed to be improved from the above aspects, integration advantages college physical education and computer technology will be effective between the reflected further lay a solid foundation for the improvement and optimization of College Physical Education.

\section{REFERENCE:}

[1] Jie Jin computer technology in college PE teaching [J]. Automation and Instrumentation, 2015,10: 147-148.

[2] Fan Liping Application of Multimedia Technology in College Physical Education related to [J] Science and Technology Information, 2014,14: 185-186.

[3] Wang Network Technology in College Physical Education Teaching [J] electronic production, 2014,13: 133-134.

[4] Sun Meng Discussion computer "virtual reality" technology in College Physical Training Application [J] electronic test, 2013,22: 61-62.

[5] Guoguang Nan Wang Xiaoling, YUN Yonggang Zhu Yi On more computer technology in college sports teaching [J] brand (theories monthly), 2011,01: 89. 